\title{
miR-196b, miR-378a and miR-486 are predictive biomarkers for the efficacy of vaccine treatment in colorectal cancer
}

\author{
YOSHITARO SHINDO ${ }^{1}$, SHOICHI HAZAMA ${ }^{1}$, YUSUKE NAKAMURA ${ }^{2}$, YUKA INOUE ${ }^{1}$, \\ SHINSUKE KANEKIYO ${ }^{1}$, NOBUAKI SUZUKI ${ }^{1}$, HIROKO TAKENOUCHI ${ }^{1}$, RYOUICHI TSUNEDOMI $^{1}$, \\ MASAO NAKAJIMA ${ }^{1}$, TOMIO UENO ${ }^{1}$, SHIGERU TAKEDA ${ }^{1}$, \\ SHIGEFUMI YOSHINO ${ }^{1}$, KIYOTAKA OKUNO ${ }^{3}$, YUSUKE FUJTTA ${ }^{4}$, \\ YOSHIHIKO HAMAMOTO ${ }^{4}$, YUTAKAKAWAKAMI ${ }^{5}$, MASAAKI OKA ${ }^{1}$ and HIROAKI NAGANO ${ }^{1}$
}

\begin{abstract}
${ }^{1}$ Department of Gastroenterological, Breast and Endocrine Surgery, Yamaguchi University Graduate School of Medicine, Ube, Yamaguchi 755-8505, Japan; ${ }^{2}$ Department of Medicine and Surgery, The University of Chicago, Chicago, IL 60637, USA;

${ }^{3}$ Department of Surgery, Kinki University Faculty of Medicine, Osakasayama, Osaka 589-8511;

${ }^{4}$ Department of Computer Science and Systems Engineering, Faculty of Engineering,

Yamaguchi University, Ube, Yamaguchi 755-8611; ${ }^{5}$ Division of Cellular Signaling, Institute for Advanced Medical Research; Keio University School of Medicine, Tokyo 160-8582, Japan
\end{abstract}

Received February 17, 2016; Accepted March 9, 2017

DOI: $10.3892 / \mathrm{ol} .2017 .6303$

\begin{abstract}
MicroRNAs (miRNAs/miRs) regulate the levels of transcripts and serve a critical function in the regulation of tumor microenvironments. Therefore, miRNA levels in cancer tissues are thought to be potential biomarkers for immunotherapy. From a phase I trial of a vaccine treatment using 5 human leukocyte antigen (HLA)-A*2402-restricted peptides (registration no. UMIN000004948), colorectal cancer (CRC) tissues were obtained from 8 patients and normal colorectal tissues from 5 patients via surgery. From a phase II trial using the same peptides (registration no. UMIN000001791), CRC tissues were obtained from 16 patients from the HLA-A*2402-matched group and 10 patients from the HLA-A*2402-unmatched group. These tissues were used for miRNA microarray analysis. As the first step, cancer tissues from the phase I study were used and 10 candidate miRNAs were selected by comparing the
\end{abstract}

Correspondence to: Professor Hiroaki Nagano, Department of Gastroenterological, Breast and Endocrine Surgery, Yamaguchi University Graduate School of Medicine, 1-1-1 Minami-Kogushi, Ube, Yamaguchi 755-8505, Japan

E-mail: hnagano@yamaguchi-u.ac.jp

Abbreviations: miRNA/miR, microRNA; HLA, human leukocyte antigen; CRC, colorectal cancer; CTL, cytotoxic T lymphocytes; $\mathrm{RNF} 43$, ring finger protein 43; TOMM34, $34 \mathrm{kDa}$-translocase of the outer mitochondrial membrane; KOC1, insulin-like growth factor-II mRNA binding protein 3; VEGFR, vascular endothelial growth factor receptor; OS, overall survival; RD, recommended dose; IFA, incomplete Freund's adjuvant; NF- $\kappa \mathrm{B}$, nuclear factor- $\kappa \mathrm{B}$

Key words: microRNA, predictive biomarker, efficacy, peptide vaccine, colorectal cancer
miRNA expression between two groups; one with improved prognosis and the other with poor prognosis. The miRNAs were subsequently validated using the cases enrolled in the phase II study. Significantly improved prognoses were identified in 16 patients in the HLA-A*2402-matched group with high expression of miR-196b-5p and low expression of miR-378a-3p and miR-486-5p. There was no difference in prognosis in the 10 patients in the HLA-A*2402-unmatched group. Therefore, high miR-196b expression and low miR-378a-3p and miR-486-5p expression were indicated as useful biomarkers for prediction of the efficacy of vaccine treatment for patients with metastatic CRC. In a planned phase III study, expression levels of these 3 miRNAs (miR-196b-5p, miR-378a-3p and miR-486-5p) may be useful biomarkers for assessing patients who are likely to have an improved outcome following vaccination.

\section{Introduction}

MicroRNAs (miRNAs/miRs) are small, endogenous, non-coding RNAs composed of 18-25 nucleotides that regulate gene expression at the post-transcriptional level (1). Certain miRNAs act as oncogenes or tumor suppressors and are considered to be among the key regulators of cancer progression $(2,3)$. Several previous studies have reported that miRNA levels in tumor tissues may be potential biomarkers for immunotherapy $(4,5)$.

Active immunotherapy using tumor-associated antigen-derived epitope peptides $(6,7)$, which aims to induce an in vivo response from tumor-specific cytotoxic $\mathrm{T}$ lymphocytes (CTLs), requires the preservation of the host immune system as indicated in the 2011 US Food and Drug Administration guidance report for therapeutic cancer vaccines (8). However, since advanced-stage patients with poor immune status are usually allowed to enroll into clinical studies in early-phase drug development, it is often difficult to evaluate the clinical 
benefit of these treatments (9). Therefore, it is necessary to identify predictive biomarkers to select patients who are likely to respond well and induce responses from specific CTLs to epitope peptides $(10,11)$.

The authors of the present study previously reported a phase I study where 5 epitope peptides were administered to patients with advanced-stage colon cancer (6). Of these, 3 peptides were derived from oncoantigens: Ring finger protein 43 (RNF43) (12), $34 \mathrm{kDa}$ translocase of the outer mitochondrial membrane (TOMM34) (13) and insulin growth factor-II mRNA binding protein 3 (KOC1, also known as IMP3) (14), and the remaining 2 peptides were derived from vascular endothelial growth factor receptors (VEGFRs) $(15,16)$. A phase II study using the same vaccine regimen in combination with oxaliplatin-based chemotherapy was performed to further verify the safety and the potential of the vaccine to induce CTLs and to improve overall survival (OS) (17). In these studies, a high CTL response following vaccination and an injection site skin reaction were revealed to be potential markers for the outcome of vaccine treatment (6), and a low neutrophil/lymphocyte ratio was also a potential marker for improved survival time of vaccinated patients (17).

The purpose of the present study was to identify novel biomarkers in order to predict the efficacy of immunotherapies prior to treatment, and to use such information to select patients who are likely to exhibit improved treatment outcomes following vaccination. The results of a comprehensive miRNA microarray analysis of cancer tissues are presented in the present study, and a number of miRNAs were identified as novel biomarkers for predicting the efficiency of active immunotherapies.

\section{Materials and methods}

Summary of the phase I study. The detailed protocol of the phase I study (UMIN clinical trial registration no. UMIN000004948) was described previously (6). Enrollment criteria were as follows: i) Histological confirmation of colorectal cancer (CRC) without surgical resection; ii) failure to respond to previous standard chemotherapy or intolerance to standard therapy and iii) positive DNA typing result for human leukocyte antigen (HLA)-A*2402.

The phase I study was primarily conducted to evaluate the safety and to investigate the recommended dose (RD) of these peptides. Good Manufacturing Practice grade RNF43-721 (NSQPVWLCL) (18), TOMM34-299 (KLRQEVKQNL) (13), KOC1 (IMP-3)-508 (KTVNELQNL) (19), VEGFR1-1084 (SYGVLLWEI) (20) and VEGFR2-169 (RFVPDGNRI) (21) peptides restricted with HLA-A*2402 were used. Dose escalation was performed in 3 patients with doses of $0.5,1$, and $3 \mathrm{mg}$ for each peptide. Each peptide was mixed with $0.5 \mathrm{ml}$ of incomplete Freund's adjuvant (IFA) and administered to patients subcutaneously into the thigh or axilla regions on days $1,8,15$, and 22 of a 28-day treatment course. According to the results of this previous study, it was decided that the $\mathrm{RD}$ of each peptide was $3.0 \mathrm{mg}$, and a dose of $3.0 \mathrm{mg}$ was administered to an additional 3 patients to confirm the safety of the peptides.

Next, a single injection of a cocktail of 5 peptides was performed, and this was expected to induce immune responses at the same level as separate injections of each of the 5 peptides. The cocktail of the 5 peptides (at the dose of $3 \mathrm{mg}$ ) was administered to 6 patients. A total of 8 out of 18 HLA-A*2402-positive CRC patients enrolled in the phase I clinical trial were available for miRNA analysis in the present study.

Summary of the phase II study. To evaluate the clinical benefits of cancer vaccination treatment, a phase II trial (UMIN clinical trial registration no. UMIN000001791) was conducted using the previously described 5 peptides. The phase II trial was a non-randomized, HLA-A status double-blind study. The detailed protocol of this study was described previously (17). Briefly, the therapy consisted of a cocktail of 5 therapeutic epitope peptides (the same as those used in the phase I study), in addition to oxaliplatin-based chemotherapy. Although the peptides used in the phase II study were HLA-A*2402 restricted peptides, the same regime of peptide cocktail and oxaliplatin-based chemotherapy was administered to all enrolled patients, whose HLA-A status was double-blinded. The cocktail of ( $3 \mathrm{mg}$ of each peptide) was mixed with $1.5 \mathrm{ml}$ IFA and administered subcutaneously into the thigh or axilla regions once per week for 13 weeks. The vaccination schedule was subsequently reduced to once every 2 weeks. Vaccination was continued even if the disease progressed when the patient wished and a primary doctor who provided additional chemotherapies agreed. Enrollment criteria for the phase II study were as follows: i) $\geq 20$ years old with histologically confirmed advanced CRC; ii) chemotherapy-naïve; iii) adequate function of organs and iv) a life expectancy of $\geq 3$ months. Between February 2009 and November 2012, 96 chemotherapy-naïve CRC patients were enrolled and their HLA-A status was masked. Among the 96 patients who were enrolled in the phase II study, 26 cases were available for miRNA analysis in the present study.

Sample collection. Among the 18 patients who participated in the phase I trial (6), tissues from 8 cases of CRC were obtained during surgery between October 2003 and June 2008. Of the patients, 4 were male and 4 were female, with an age range of 56-75 years and a mean age of 64 years. From these 8 patients, CRC tissues were obtained, and normal colorectal tissues were also obtained from surgical specimens of 5 patients between January 2004 and July 2006. Of the normal patients, 2 were male and 3 were female, with an age range of 59-75 years and a mean age of 66 years. Tissues were snap-frozen in liquid nitrogen and stored at $-80^{\circ} \mathrm{C}$. Similarly, CRC tissues were obtained from 26 patients who participated in the phase II trial of vaccine treatment in combination with oxaliplatin-based chemotherapy between October 2008 and September 2011 (17). Of these patients, 11 were male and 15 were female, with an age range of 47-82 years and a mean age of 67 years. CRC tissues were obtained from 16 cases from the HLA-A*2402-matched group and 10 cases from the HLA-A*2402-unmatched group.

All patients underwent resection of the cancer prior to phase I and II vaccine trials at Yamaguchi University Hospital (Yamaguchi, Japan). Written informed consent was obtained from all patients, and the present study was approved by the Institutional Ethics Review Boards of Yamaguchi University and was conducted in accordance with the Declaration of Helsinki. 
miRNA microarray. The median miRNA expression values in 34 cancer tissues were used as cut off values to classify patients into high or low expression group. Total RNA from CRC tissues and normal colorectal samples was analyzed by miRNA microarray. Total RNA was extracted from tissues using the mirVana miRNA Isolation kit (Thermo Fisher Scientific, Inc., Waltham, MA, USA) according to the manufacturer's protocol. The concentration and purity of RNAs was assessed with a spectrophotometer and RNA integrity was verified using an Agilent RNA 6000 Nano kit (Agilent Technologies, Inc., Santa Clara, CA, USA). The optical density (OD) 260/OD280 ratios of each sample were within 2.00-2.10, which were accepted to be adequate for microarray analysis. The miRNA array was performed using $1 \mu \mathrm{g}$ total RNA, the miRCURY LNA microRNA Array 6th generation (EXIQON; Qiagen, Inc., Valencia, CA, USA) and the GenePix 4000B (Molecular Devices, LLC; Sunnyvale, CA, USA). The relative intensity of each hybridization signal was evaluated using the Microarray Data Analysis tool (version 3.2; Filgen, Inc., Nagoya, Japan).

Statistical analysis. Following the calculation of expression signals by $\log ^{2}$ transformation of the normalized data, differentially expressed miRNAs were detected by using the fold-change value and Fisher index using Microsoft Excel 2010 (Microsoft Corporation, Redmond, WA, USA) according to the previously reported formula (22). Differences between groups were estimated using the Mann-Whitney U-test. Categorical variables were compared using $\chi^{2}$ and Fisher's exact tests. A Cox's proportional hazards model was used to estimate the hazard ratios for the treatment effect in relation to OS and miRNA expression, and OS was measured in days from the first vaccination until patient mortality (due to any cause). Survival curves were analyzed using the Kaplan-Meier method and the log-rank test. Statistical analyses were performed with JMP software (version 11; SAS Institute Inc., Cary, NC, USA) and GraphPad Prism software (version 5.0; GraphPad Software, Inc., San Diego, CA, USA). P $<0.05$ was considered to indicate a statistically significant difference.

\section{Results}

Selection of candidate miRNAs to predict the efficacy of vaccination. The expression profiles of 1,425 miRNAs in CRC tissues from 8 patients enrolled in the phase I study were analyzed. The characteristics of the 8 patients are listed in Table I. The patients were divided into 2 groups (responder and non-responder group) with 4 patients in each group. A responder is defined using the following criteria: i) Progression free survival (PFS) $>150$ days or ii) OS $>300$ days without additional chemotherapy. Criteria for non-responders were as follows: i) PFS $<90$ days and ii) OS $<200$ days.

On the basis of the relative comparison of hybridization signals, miRNAs with significant differences in expression between the responder and non-responder groups were selected. The 10 miRNAs with the most significant differences in expression between the two groups are listed in Table II.

Comparison ofmiRNA expression levels between cancer tissues and normal colorectal tissues. miRNA microarray profiles of

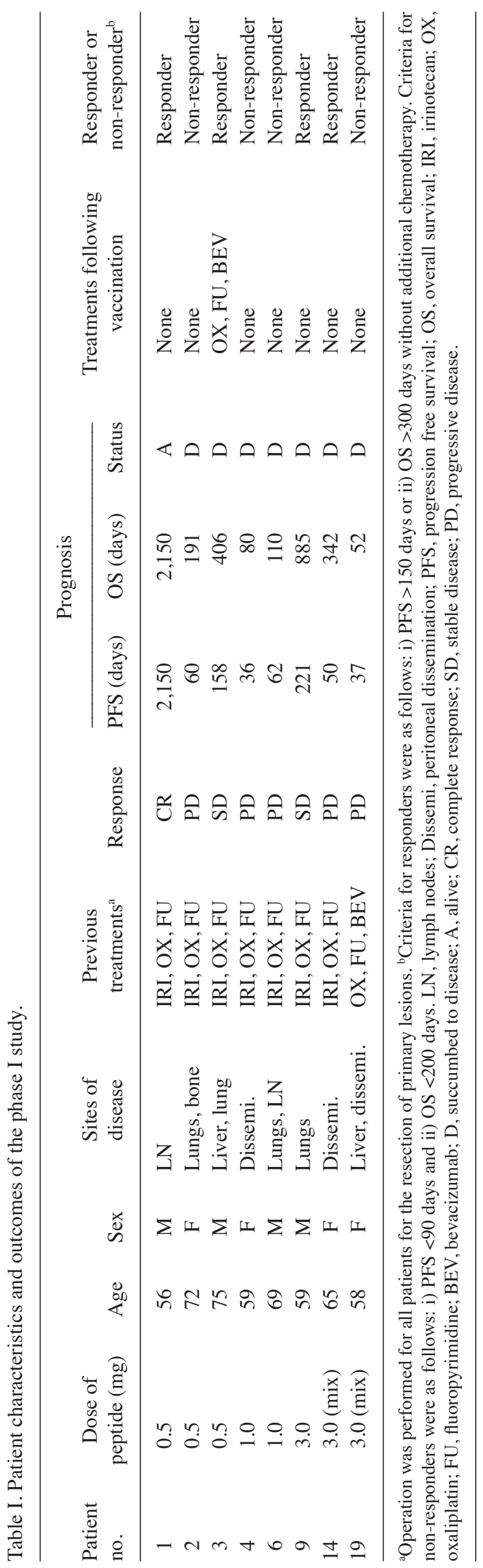


Table II. miRNA expression of cancer tissues of patients in the phase I study.

\begin{tabular}{|c|c|c|c|c|c|c|c|c|c|}
\hline \multirow[b]{3}{*}{ Rank } & \multirow{3}{*}{$\begin{array}{l}\text { Name of } \\
\text { miRNA }\end{array}$} & \multicolumn{4}{|c|}{ Signal intensity in cancer tissues } & \multirow{3}{*}{$\begin{array}{l}\log ^{2} \text { ratio } \\
\quad>0.8\end{array}$} & \multirow{3}{*}{$\begin{array}{l}\text { Fisher's } \\
\text { ratio }\end{array}$} & \multirow[b]{3}{*}{ P-value ${ }^{a}$} & \multirow{3}{*}{$\begin{array}{l}\text { miRNA expression in } \\
\text { the responder group }\end{array}$} \\
\hline & & \multicolumn{2}{|c|}{$\begin{array}{l}\text { Responder } \\
\quad(\mathrm{n}=4)\end{array}$} & \multicolumn{2}{|c|}{$\begin{array}{l}\text { Non-responder } \\
\qquad(\mathrm{n}=4)\end{array}$} & & & & \\
\hline & & Mean & $\mathrm{SD}$ & Mean & SD & & & & \\
\hline 1 & hsa-miR-142-5p & $1,606.3$ & 275.3 & $3,697.8$ & $1,734.8$ & -1.2 & 4.8 & 0.055 & Low \\
\hline 2 & hsa-miR-196b-3p & 295.7 & 83.2 & 164.2 & 26.1 & 0.8 & 4.5 & 0.024 & High \\
\hline 3 & hsa-miR-196b-5p & 678.0 & 381.6 & 172.0 & 56.5 & 2.0 & 3.6 & 0.039 & High \\
\hline 4 & hsa-miR-147b & 332.9 & 86.0 & 778.3 & 366.0 & -1.2 & 3.4 & 0.090 & Low \\
\hline 5 & hsa-miR-320b & 4480.4 & 2085.6 & 8208.7 & 1799.7 & -0.9 & 3.4 & 0.035 & Low \\
\hline 6 & hsa-miR-378a-3p & 5711.6 & 2043.9 & 9709.1 & 2499.3 & -0.8 & 3.0 & 0.048 & Low \\
\hline 7 & hsa-miR-320e & 3293.1 & 1831.7 & 6073.7 & 1557.0 & -0.9 & 2.9 & 0.060 & Low \\
\hline 8 & hsa-miR-486-5p & 289.0 & 53.4 & 516.7 & 244.3 & -0.8 & 2.7 & 0.119 & Low \\
\hline 9 & hsa-miR-378c & 950.8 & 522.4 & 1978.7 & 732.5 & -1.1 & 2.6 & 0.062 & Low \\
\hline 10 & hsa-miR-320a & 4823.1 & 2574.0 & 9183.3 & 2923.4 & -0.9 & 2.4 & 0.066 & Low \\
\hline
\end{tabular}

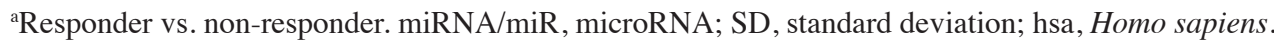

Table III. miRNA expression of cancer tissues and normal colorectal tissues.

\begin{tabular}{|c|c|c|c|c|c|c|c|}
\hline \multirow{2}{*}{$\begin{array}{l}\text { miR rank in the } \\
\text { phase I study }\end{array}$} & \multirow{2}{*}{$\begin{array}{l}\text { Name of } \\
\text { miRNA }\end{array}$} & \multicolumn{3}{|c|}{$\begin{array}{c}\text { Signal intensity in cancer } \\
\text { tissues }(n=34)\end{array}$} & \multicolumn{2}{|c|}{$\begin{array}{l}\text { Signal intensity in normal } \\
\text { colorectal tissues }(n=5)\end{array}$} & \multirow[b]{2}{*}{ P-value } \\
\hline & & Mean \pm SD $(n=34)$ & Median & Cut off value & Mean $\pm \operatorname{SD}(n=5)$ & Median & \\
\hline 1 & miR-142-5p & $1,874.4 \pm 1406.5$ & 1,419 & $<1400$ & $2,782.8 \pm 3284.3$ & 1,129 & 0.850 \\
\hline 2 & miR-196b-3p & $212.9 \pm 96.3$ & 184 & $>180$ & $119.2 \pm 15.2$ & 119 & 0.011 \\
\hline 3 & miR-196b-5p & $627.0 \pm 615.2$ & 446 & $>450$ & $105.4 \pm 10.5$ & 106 & $<0.001$ \\
\hline 4 & miR-147b & $500.5 \pm 227.6$ & 435 & $<440$ & $1243.8 \pm 188.7$ & 1213 & $<0.001$ \\
\hline 5 & miR-320b & $6079.2 \pm 2127.6$ & 5947 & $<6000$ & $6792.0 \pm 2861.0$ & 5676 & 0.850 \\
\hline 6 & $\operatorname{miR}-378 a-3 p$ & $6575.0 \pm 2459.3$ & 6496 & $<6500$ & $8035.4 \pm 2335.6$ & 9575 & 0.200 \\
\hline 7 & miR-320e & $5981.1 \pm 2301.0$ & 5764 & $<5800$ & $4623.2 \pm 1081.0$ & 4390 & 0.159 \\
\hline 8 & miR-486-5p & $358.8 \pm 115.1$ & 350 & $<350$ & $528.6 \pm 124.0$ & 483 & 0.003 \\
\hline 9 & $\operatorname{miR}-378 c$ & $1341.7 \pm 702.0$ & 1210 & $<1200$ & $2062.2 \pm 707.0$ & 2056 & 0.056 \\
\hline 10 & miR-320a & $6647.1 \pm 2666.4$ & 6426 & $<6500$ & $7695.8 \pm 2724.2$ & 6413 & 0.437 \\
\hline
\end{tabular}

${ }^{a}$ Normal vs. cancer tissues. miRNA/miR, microRNA; SD, standard deviation.

cancer tissues from the 8 patients enrolled in the phase I study and 26 patients enrolled in the phase II study were analyzed. Subsequently, the miRNA microarray profiles of the cancer tissues were compared with the microarray profiles of 5 normal colorectal tissues using the Mann-Whitney U-test. miR-196b-3p $(\mathrm{P}=0.011)$ and miR-196b-5p $(\mathrm{P}<0.001)$ were demonstrated to be upregulated compared with the normal tissues (Table III). In addition, miR-147b $(\mathrm{P}<0.001)$, miR-486-5p $(\mathrm{P}=0.003)$ and miR-378c ( $\mathrm{P}=0.056$; not significant) were downregulated in CRC tissues compared with normal tissues. A cut-off value for each miRNA (miR-142-5p, -196b-3p, -196b-5p, -147b, $-320 b,-378 a-3 p,-320 e,-486-5 p,-378 c$ and $-320 a)$ was set at $1,400,180,450,440,6,000,6,500,5,800,350,1,200$ and 6,500 , respectively according to the median expression value $(1,419,184,446,435,5,947,6,496,5,764,350,1,210$, and 6,426, respectively) in 34 cancer tissues. The patients were classified into high or low expression groups based on a cut-off value of miRNA expression for subsequent analysis (Table III).

Validation of candidate miRNA expression in patients enrolled in the phase II study. A total of 24 CRC tissues from the phase II study were analyzed using miRNA microarray. The profiles of the 26 patients are summarized in Table IV. A total of 10 candidate miRNAs were selected by analyzing cancer 
tissues in the phase I study (Table II) and the clinical outcome of 16 patients in the HLA-A*2402-matched group in the phase II study, where the same peptide vaccines were used in combination with oxaliplatin-based chemotherapy (Table V).

The expression levels of 10 candidate miRNAs were subsequently examined in 16 patients in the HLA-A*2402-matched group (Fig. 1). Significantly improved prognosis was observed in the patients with increased ( $>450)$ miR-196b-5p expression (hazard ratio $=0.099, \mathrm{P}=0.002$, Table V; $\mathrm{P}=0.001$, Fig. 1A), decreased $(<6,500)$ miR-378a-3p expression (hazard ratio $=0.223, \mathrm{P}=0.025$, Table V; $\mathrm{P}=0.022$, Fig. 1B) and decreased $(<350) \mathrm{miR}-486-5 \mathrm{p}$ expression (hazard ratio $=0.248, \mathrm{P}=0.023$, Table $\mathrm{V} ; \mathrm{P}=0.017$; Fig. $1 \mathrm{C}$ ) compared with the other patients with high or low expression of each miRNA. On the other hand, there was no difference in the prognoses in 10 patients in the HLA-A*2402-unmatched group according to expression levels of miR-196b-5p $(\mathrm{P}=0.271$; Fig. 1D), miR-378a-3p ( $\mathrm{P}=0.757$; Fig. 1E) and miR-486-5p ( $\mathrm{P}=0.562$; Fig. $1 \mathrm{~F})$.

\section{Discussion}

Due to the rapid and impressive progress made in the field of cancer immunology (23), a large number of novel vaccine approaches for the treatment of cancer are being developed $(24,25)$. However, useful biomarkers that predict the clinical outcome of immunotherapy remain to be identified (10). In addition, only a small number of immunological or other biomarkers are available in clinical trials for immunotherapy (26). The identification of biomarkers would be useful for selecting appropriate patient populations for evaluation at earlier stages of clinical trials and for developing vaccines for cancer treatment $(10,11)$. In the present study, the efficacy of novel biomarkers for immunotherapy was investigated by performing miRNA microarray analysis of cancer tissues and by comparing the clinical outcomes of phase I and II studies $(6,17)$ testing a vaccine treatment for metastatic CRC using a cocktail of 5 HLA-A*2402 restricted peptides.

As the first step, miRNA expression patterns in $8 \mathrm{CRC}$ tissues obtained from the patients in the phase I study were examined, and 10 candidate miRNAs were selected as potential predictive markers for the efficacy of immunotherapy by comparing miRNA expression of the responder and non-responder groups, one with improved prognosis and the other with poorer prognosis, using Fisher's ratio (Table II).

Subsequently, the expression levels of the 10 candidate miRNAs were examined in 34 cancer tissues ( 8 cases from the phase I study and 26 cases from the phase II study) and compared with the expression levels in 5 normal colorectal tissues. Upregulation of miR-196b-3p $(\mathrm{P}=0.011)$ and miR-196b-5p $(\mathrm{P}<0.001)$, and downregulation of miR-147b $(\mathrm{P}<0.001)$, miR-486-5p $(\mathrm{P}=0.003)$ and $\mathrm{miR}-378 \mathrm{c}(\mathrm{P}=0.056$; not significant) were observed in the cancer tissues (Table III). Cut-off values for each miRNA were set according to the median expression value in 34 cancer tissues (Table III), and patients were classified into 2 groups (high and low expression) for subsequent analysis (Table V).

The 10 candidate miRNAs were analyzed for association with prognoses of patients $(n=26)$ enrolled in the phase II
Table IV. Characteristics of patients in the phase II study.

$$
\text { HLA-A } 2402
$$

\begin{tabular}{lccc}
\cline { 2 - 3 } Characteristics & $\begin{array}{c}\text { Matched } \\
(\mathrm{n}=16)\end{array}$ & $\begin{array}{c}\text { Unmatched } \\
(\mathrm{n}=10)\end{array}$ & P-value \\
\hline Sex & & & \\
Male & 5 & 6 & $>0.05$ \\
Female & 11 & 4 & \\
Age & & & $>0.05$ \\
Mean & 69.8 & 63.5 & \\
Range & $58-82$ & $47-76$ & $>0.05$ \\
Unresectable site & & & \\
Liver & 8 & 7 & \\
Lung & 5 & 5 & \\
Dissemination & 1 & 2 & \\
Bone & 0 & 1 & \\
Lymph node & 3 & 3 & \\
Other & 1 & 1 &
\end{tabular}

Resection of

primary lesion

$\begin{array}{lcc}\text { Yes } & 16 & 10 \\ \text { No } & 0 & 0\end{array}$

Chemotherapy

FOLFOX

XELOX

Bevacizumab

15

10

$>0.05$

Location of cancer

Colon

10

01

Rectum

12

5

$>0.05$

45

FOLFOX, infusional fluorouracil, leucovorin, and oxaliplatin; XELOX, capecitabine and oxaliplatin; HLA, human leukocyte antigen.

study. HLA-A*2402-restricted peptides were used in the phase II study. Therefore, the HLA-A*2402-matched group $(n=16)$ was considered to be the immunological treatment group and the HLA-A*2402-unmatched group $(n=10)$ the control group. Significantly improved prognoses were observed in the HLA-A*2402-matched group with increased $(>450)$ miR-196b-5p expression (hazard ratio $=0.099, \mathrm{P}=0.002$, Table V; log-rank test, $\mathrm{P}=0.001$, Fig. $1 \mathrm{~A})$, decreased $(<6,500) \mathrm{miR}-378 \mathrm{a}-3 \mathrm{p}$ expression (hazard ratio $=0.223, \mathrm{P}=0.025$, Table $\mathrm{V}$; log-rank test, $\mathrm{P}=0.022$, Fig. 1B) and decreased $(<350)$ miR-486-5p expression (hazard ratio $=0.248, \mathrm{P}=0.023$, Table V; log-rank test, $\mathrm{P}=0.017$, Fig. 1C) compared with the other patients with high or low expression levels of each miRNA. However, there was no difference in prognosis in the HLA-A*2402-unmatched group $(n=10)$ according to the expression of miR-196b-5p ( $\mathrm{P}=0.271$; Fig. 1D), miR-378a-3p ( $\mathrm{P}=0.757$; Fig. $1 \mathrm{E})$ and miR-486-5p $(\mathrm{P}=0.562$; Fig. 1F). These results indicated that these miRNAs may be used as biomarkers for immunotherapy.

The upregulation of miR-196b has previously been reported in lung adenocarcinoma, oral cancer, $\mathrm{CRC}$, leukemia 
Table V. Overall survival according to miRNA expression ( $n=16$, patients with HLA-A*2402).

\begin{tabular}{|c|c|c|c|c|c|c|c|}
\hline \multirow[b]{2}{*}{$\begin{array}{l}\text { miR rank in the } \\
\text { phase I study }\end{array}$} & \multirow[b]{2}{*}{$\begin{array}{l}\text { Name of } \\
\text { microRNA }\end{array}$} & \multirow[b]{2}{*}{$\begin{array}{l}\text { Cut off } \\
\text { value }^{\text {a }}\end{array}$} & \multicolumn{2}{|c|}{ Number of patients } & \multirow[b]{2}{*}{ Hazard ratio } & \multirow[b]{2}{*}{$95 \%$ CI } & \multirow[b]{2}{*}{ P-value } \\
\hline & & & $\begin{array}{c}\text { Low } \\
\text { expression }\end{array}$ & $\begin{array}{c}\text { High } \\
\text { expression }\end{array}$ & & & \\
\hline 1 & $\operatorname{miR}-142-5 p$ & $<1,400$ & 8 & 8 & 0.785 & $0.243-2.534$ & 0.678 \\
\hline 2 & miR-196b-3p & $>180$ & 7 & 9 & 0.447 & $0.136-1.463$ & 0.178 \\
\hline 3 & miR-196b-5p & $>450$ & 7 & 9 & 0.099 & $0.014-0.441$ & 0.002 \\
\hline 4 & miR-147b & $<440$ & 8 & 8 & 0.320 & $0.084-1.041$ & 0.059 \\
\hline 5 & miR-320b & $<6,000$ & 10 & 6 & 0.933 & $0.292-3.219$ & 0.908 \\
\hline 6 & miR-378a-3p & $<6,500$ & 9 & 7 & 0.223 & $0.046-0.832$ & 0.025 \\
\hline 7 & miR-320e & $<5,800$ & 7 & 9 & 0.624 & $0.165-2.000$ & 0.435 \\
\hline 8 & miR-486-5p & $<350$ & 9 & 7 & 0.248 & $0.070-0.820$ & 0.023 \\
\hline 9 & $\operatorname{miR}-378 \mathrm{c}$ & $<1,200$ & 5 & 11 & 0.630 & $0.139-2.125$ & 0.475 \\
\hline 10 & miR-320a & $<6,500$ & 9 & 7 & 0.706 & $0.217-2.308$ & 0.556 \\
\hline
\end{tabular}

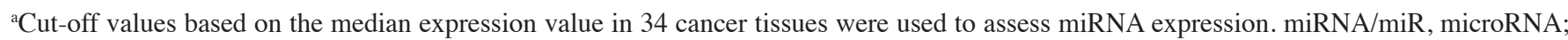
HLA, human leukocyte antigen; SD, standard deviation; has, Homo sapiens; CI, confidence interval.

A HLA-A*2402 matched group

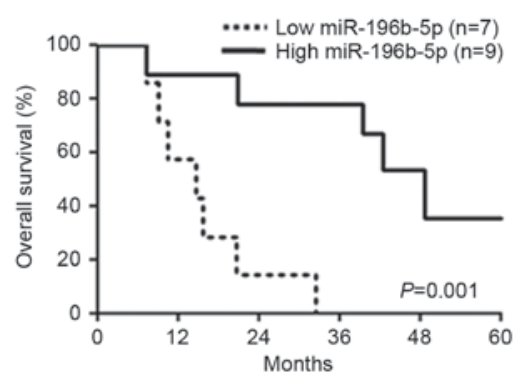

C
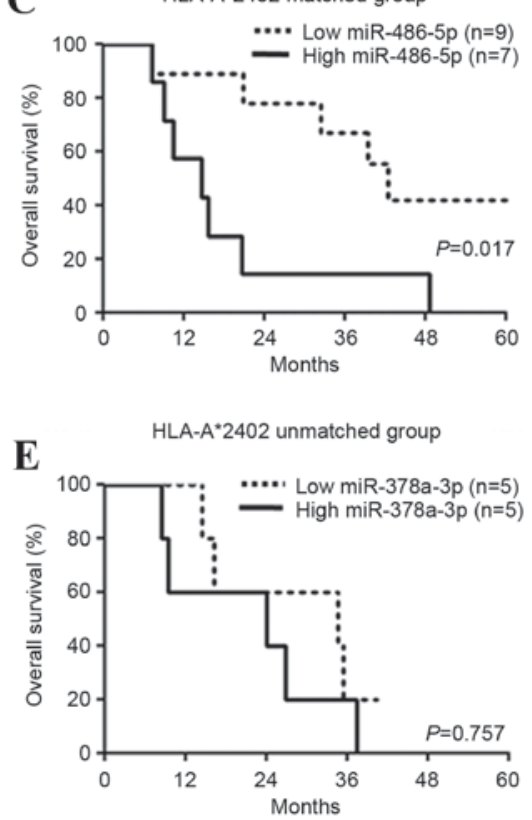

B HLA-A*2402 matched group

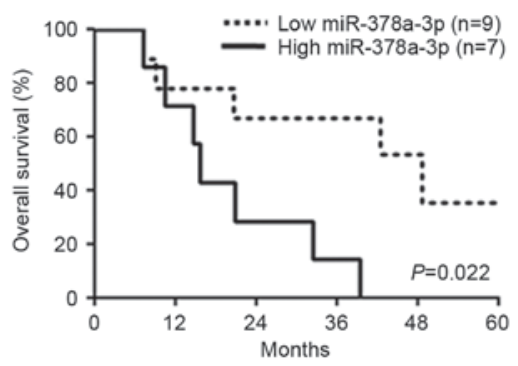

D HLA-A*2402 unmatched group

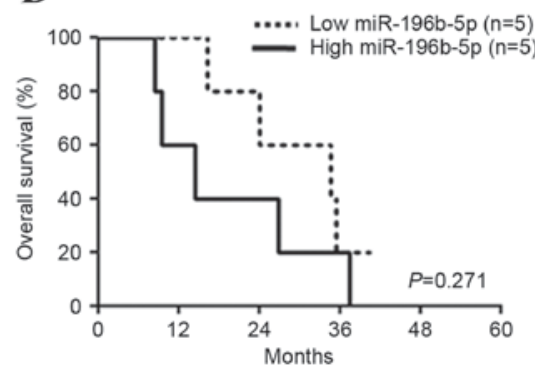

F HLA-A*2402 unmatched group

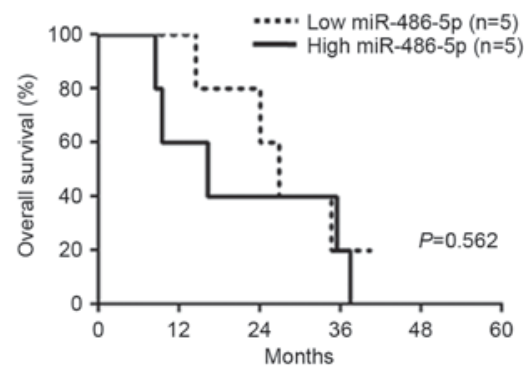

Figure 1. Overall survival of the 16 patients in the HLA-A 2402 -matched group and the 10 patients in the HLA-A 2402 -unmatched group treated in the phase II study, according to expression levels of miRNAs, as determined by Kaplan-Meier analysis. (A) miR-196b-5p and HLA-A*2402-matched group; (B) miR-378a-3p and HLA-A"2402-matched group; (C) miR-486-5p and HLA-A"2402-matched group; (D) miR-196b-5p and HLA-A*2402-unmatched group; (E) miR-378a-3p and HLA-A*2402-unmatched group and (F) miR-486-5p and HLA-A*2402-unmatched group. The solid line indicates high miRNA expression, and the dashed line indicates low miRNA expression. Statistical analysis was performed using the log-rank test. HLA, human leukocyte antigen; miRNA/miR, microRNA. 
and lymphoma, and has been associated with the malignant phenotype of these types of cancer (27-30). By contrast, the results of the present study indicated that high miR-196b expression appeared to be associated with improved prognosis for patients treated with immunotherapy (Tables II and V; Fig. 1A). High miR-196b expression levels may be associated with the augmentation of the immune response to cancer, which may explain these paradoxical results. miR-196b has previously been reported to be a potential target of inflammatory signals, as it is known to be overexpressed in the inflammatory epithelial lesions of patients with Crohn's disease (31).

The cancer tissues used in the present study may contain not only cancer cells but also tumor infiltrating immune cells, as this has previously been suggested to be a biomarker for improved prognosis of CRC (32). The results of the present study indicated that high miR-196b expression may be used as a biomarker for predicting whether patients respond to immunotherapy, although the function of miR-196b requires clarification through further investigations.

miR-378a has been reported as a tumor suppressor and to be downregulated in CRC (33). However, the results of the present study indicated that reduced expression levels of miR-378a-3p were significantly associated with improved prognosis (Table V; Fig. 1C). miR-378a was also reported to promote cell survival, tumor growth and angiogenesis through repression of the expression of two tumor suppressors, SUFU negative regulator of hedgehog signaling and FUS RNA binding protein (34). As miR-378a is able to act as oncogene or a tumor suppressor, its function is complicated $(33,34)$. Therefore, it is essential to further investigate the function of miR-378a-3p in the future.

miR-486 has been reported to be a cancer-suppressor miRNA, and it is often downregulated in a number of cancer types in multiple organs $(35,36)$. Downregulation of miR-486 has been reported to contribute to tumor progression and metastasis (35). However, the results of the present study indicated that low expression of miR-486-5p was significantly associated with improved prognosis (Table V; Fig. 1E). Since miR-486 has been reported to sustain the activity of nuclear factor- $\kappa \mathrm{B}(\mathrm{NF}-\kappa \mathrm{B})$ by disrupting multiple NF- $\mathrm{NB}$-negative feedback loops (37) and suppressing the antitumor immunity of the host $(38,39)$. Downregulation of miR-486 may reduce $\mathrm{NF}-\kappa \mathrm{B}$ expression and suppress immune-suppressive cells in the microenvironment of the tumor.

In conclusion, high miR-196b-5p, low miR-378a-3p and low miR-486-5p expression levels may be considered as novel biomarkers to predict the efficacy of immunotherapy. However, the results of the present study are preliminary, and the function of miRNAs in immune responses remain unclear. In a planned phase III study, it may be applicable to use these miRNAs as biomarkers to assess the selection of patients who may expect an improved outcome with the vaccine treatment.

\section{Acknowledgements}

The present study was part of the research program of the Project for Development of Innovative Research on Cancer Therapeutics, the Japan Agency for Medical Research and Development. The authors would like to thank Dr. Takuya
Tsunoda and Dr. Koji Yoshida (Laboratory of Molecular Medicine, Human Genome Center, Institute of Medical Science, The University of Tokyo, Tokyo, Japan) for their excellent advice and cooperation and providing all the peptides.

\section{References}

1. Zaharie F, Muresan MS, Petrushev B, Berce C, Gafencu GA, Selicean S, Jurj A, Cojocneanu-Petric R, Lisencu CI, Pop LA, et al: Exosome-carried microRNA-375 inhibits cell progression and dissemination via Bcl-2 blocking in colon cancer. J Gastrointestin Liver Dis 24: 435-443, 2015.

2. Takeyama H, Yamamoto H, Yamashita S, Wu X, Takahashi $H$, Nishimura J, Haraguchi N, Miyake Y, Suzuki R, Murata K, et al: Decreased miR-340 expression in bone marrow is associated with liver metastasis of colorectal cancer. Mol Cancer Ther 13: 976-985, 2014.

3. Konno Y, Dong P, Xiong Y, Suzuki F, Lu J, Cai M, Watari H, Mitamura T, Hosaka M, Hanley SJ, et al: MicroRNA-101 targets EZH2, MCL-1 and FOS to suppress proliferation, invasion and stem cell-like phenotype of aggressive endometrial cancer cells. Oncotarget 5: 6049-6062, 2014.

4. Achberger S, Aldrich W, Tubbs R, Crabb JW, Singh AD and Triozzi PL: Circulating immune cell and microRNA in patients with uveal melanoma developing metastatic disease. Mol Immunol 58: 182-186, 2014.

5. Okada H, Kohanbash G and Lotze MT: MicroRNAs in immune regulation-opportunities for cancer immunotherapy. Int $\mathbf{J}$ Biochem Cell Biol 42: 1256-1261, 2010.

6. Hazama S, Nakamura Y, Takenouchi H, Suzuki N, Tsunedomi R, Inoue Y, Tokuhisa Y, Iizuka N, Yoshino S, Takeda K, et al: A phase I study of combination vaccine treatment of five therapeutic epitope-peptides for metastatic colorectal cancer; safety, immunological response, and clinical outcome. J Transl Med 12: 63, 2014.

7. Suzuki N, Hazama S, Ueno T, Matsui H, Shindo Y, Iida M, Yoshimura K, Yoshino S, Takeda K and Oka M: A phase I clinical trial of vaccination with KIF20A-derived peptide in combination with gemcitabine for patients with advanced pancreatic cancer. J Immunother 37: 36-42, 2014.

8. U.S. Department of Health and Human Services FaDA, October 2011: U.S. Department of Health and Human Services, Food and Drug Administration, October 2011: Guidance for Industry. Clinical Considerations for Therapeutic Cancer Vaccines, 2011.

9. Nagorsen D and Thiel E: Clinical and immunologic responses to active specific cancer vaccines in human colorectal cancer. Clin Cancer Res 12: 3064-3069, 2006.

10. Copier J, Whelan M and Dalgleish A: Biomarkers for the development of cancer vaccines: Current status. Mol Diagn Ther 10: 337-343, 2006.

11. Whiteside TL: Immune responses to cancer: Are they potential biomarkers of prognosis? Front Oncol 3: 107, 2013.

12. Yagyu R, Furukawa Y, Lin YM, Shimokawa T, Yamamura T and Nakamura Y: A novel oncoprotein RNF43 functions in an autocrine manner in colorectal cancer. Int J Oncol 25: 1343-1348, 2004.

13. Shimokawa T, Matsushima S, Tsunoda T, Tahara H, Nakamura Y and Furukawa Y: Identification of TOMM34, which shows elevated expression in the majority of human colon cancers, as a novel drug target. Int J Oncol 29: 381-386, 2006.

14. Kikuchi T, Daigo Y, Katagiri T, Tsunoda T, Okada K, Kakiuchi S, Zembutsu H, Furukawa Y, Kawamura M, Kobayashi K, et al: Expression profiles of non-small cell lung cancers on cDNA microarrays: Identification of genes for prediction of lymph-node metastasis and sensitivity to anti-cancer drugs. Oncogene 22: 2192-2205, 2003.

15. Olofsson B, Korpelainen E, Pepper MS, Mandriota SJ, Aase K, Kumar V, Gunji Y, Jeltsch MM, Shibuya M, Alitalo K and Eriksson U: Vascular endothelial growth factor B (VEGF-B) binds to VEGF receptor-1 and regulates plasminogen activator activity in endothelial cells. Proc Natl Acad Sci USA 95: 11709-11714, 1998.

16. Millauer B, Wizigmann-Voos S, Schnurch H, Martinez R, Møller NP, Risau W and Ullrich A: High affinity VEGF binding and developmental expression suggest Flk-1 as a major regulator of vasculogenesis and angiogenesis. Cell 72: 835-846, 1993.

17. Hazama S, Nakamura Y, Tanaka H, Hirakawa K, Tahara K, Shimizu R, Ozasa H, Etoh R, Sugiura F, Okuno K, et al: A phase II study of five peptides combination with oxaliplatin-based chemotherapy as a first-line therapy for advanced colorectal cancer (FXV study). J Transl Med 12: 108, 2014. 
18. Uchida N, Tsunoda T, Wada S, Furukawa Y, Nakamura Y and Tahara H: Ring finger protein 43 as a new target for cancer immunotherapy. Clin Cancer Res 10: 8577-8586, 2004.

19. Suda T, Tsunoda T, Daigo Y, Nakamura Y and Tahara H: Identification of human leukocyte antigen-A24-restricted epitope peptides derived from gene products upregulated in lung and esophageal cancers as novel targets for immunotherapy. Cancer Sci 98: 1803-1808, 2007.

20. Ishizaki H, Tsunoda T, Wada S, Yamauchi M, Shibuya M and Tahara H: Inhibition of tumor growth with antiangiogenic cancer vaccine using epitope peptides derived from human vascular endothelial growth factor receptor 1. Clin Cancer Res 12: 5841-5849, 2006.

21. Wada S, Tsunoda T, Baba T, Primus FJ, Kuwano H, Shibuya M and Tahara H: Rationale for antiangiogenic cancer therapy with vaccination using epitope peptides derived from human vascular endothelial growth factor receptor 2. Cancer Res 65: 4939-4946, 2005.

22. Iizuka N, Oka M, Yamada-Okabe H, Nishida M, Maeda Y, Mori N, Takao T, Tamesa T, Tangoku A, Tabuchi H, et al: Oligonucleotide microarray for prediction of early intrahepatic recurrence of hepatocellular carcinoma after curative resection Lancet 361: 923-929, 2003.

23. Boon $T$ and van der Bruggen P: Human tumor antigens recognized by T lymphocytes. J Exp Med 183: 725-729, 1996.

24. Okabe H, Satoh S, Kato T, Kitahara O, Yanagawa R, Yamaoka Y, Tsunoda T, Furukawa Y and Nakamura Y: Genome-wide analysis of gene expression in human hepatocellular carcinomas using cDNA microarray: Identification of genes involved in viral carcinogenesis and tumor progression. Cancer Res 61: 2129-2137, 2001.

25. Okuno K, Sugiura F, Itoh K, Yoshida K, Tsunoda T and Nakamura Y: Recent advances in active specific cancer vaccine treatment for colorectal cancer. Curr Pharm Biotechnol 13: 1439-1445, 2012.

26. Kijima T, Hazama S, Tsunedomi R, Tanaka H, Takenouchi H, Kanekiyo S, Inoue Y, Nakashima M, Iida M, Sakamoto K, et al: Micro RNA-6826 and -6875 in plasma are valuable non-invasive biomarkers that predict the efficacy of vaccine treatment against metastatic colorectal cancer. Oncol Rep 37: 23-30, 2017.

27. Li X, Shi Y, Yin Z, Xue X and Zhou B: An eight-miRNA signature as a potential biomarker for predicting survival in lung adenocarcinoma. J Transl Med 12: 159, 2014.

28. Lu YC, Chang JT, Liao CT, Kang CJ, Huang SF, Chen IH, Huang CC, Huang YC, Chen WH, Tsai CY, et al: OncomiR-196 promotes an invasive phenotype in oral cancer through the NME4-JNK-TIMP1-MMP signaling pathway. Mol Cancer 13 $218,2014$.
29. Ge J, Chen Z, Li R, Lu T and Xiao G: Upregulation of microRNA-196a and microRNA-196b cooperatively correlate with aggressive progression and unfavorable prognosis in patients with colorectal cancer. Cancer Cell Int 14: 128, 2014

30. Pan Y, Meng M, Zhang G, Han H and Zhou Q: Oncogenic microRNAs in the genesis of leukemia and lymphoma. Curr Pharm Des 20: 5260-5267, 2014.

31. Chen WX, Ren LH and Shi RH: Implication of miRNAs for inflammatory bowel disease treatment: Systematic review. World J Gastrointest Pathophysiol 5: 63-70, 2014.

32. Galon J, Mlecnik B, Bindea G, Angell HK, Berger A, Lagorce C, Lugli A, Zlobec I, Hartmann A, Bifulco C, et al: Towards the introduction of the 'Immunoscore' in the classification of malignant tumours. J Pathol 232: 199-209, 2014.

33. Zhang GJ, Zhou H, Xiao HX, Li Y and Zhou T: MiR-378 is an independent prognostic factor and inhibits cell growth and invasion in colorectal cancer. BMC Cancer 14: 109, 2014.

34. Lee DY, Deng Z, Wang CH and Yang BB: MicroRNA-378 promotes cell survival, tumor growth and angiogenesis by targeting SuFu and Fus-1 expression. Proc Natl Acad Sci USA 104: 20350-20355, 2007.

35. Chen H, Ren C, Han C, Wang D, Chen Y and Fu D: Expression and prognostic value of miR-486-5p in patients with gastric adenocarcinoma. PLoS One 10: e0119384, 2015.

36. Wang J, Tian X, Han R, Zhang X, Wang X, Shen H, Xue L, Liu Y, Yan X, Shen J, et al: Downregulation of miR-486-5p contributes to tumor progression and metastasis by targeting protumorigenic ARHGAP5 in lung cancer. Oncogene 33: 1181-1189, 2014

37. Song L, Lin C, Gong H, Wang C, Liu L, Wu J, Tao S, Hu B, Cheng SY, Li M and Li J: miR-486 sustains NF- $\kappa$ B activity by disrupting multiple NF-кB-negative feedback loops. Cell Res 23: 274-289, 2013.

38. Fisher DT, Appenheimer MM and Evans SS: The two faces of IL-6 in the tumor microenvironment. Semin Immunol 26: 38-47, 2014.

39. Gajewski TF, Schreiber H and Fu YX: Innate and adaptive immune cells in the tumor microenvironment. Nat Immunol 14: 1014-1022, 2013 